\title{
Torakal Vertebra Görüntülemesinde Simülasyon ve Üç Boyutlu Modellemenin Radyolojik Tanı ve Cerrahi Öncesi Planlama Üzerinde Etkileri
}

\author{
The Effects of Simulation and Three-Dimensional Modeling on \\ Radiological Diagnosis and Pre-Surgical Planning in Thoracic Vertebra \\ Imaging
}

\author{
${ }^{1}$ Nevin Aydın, ${ }^{2}$ İsmail Kaya, ${ }^{3}$ Reşit Buğra Hüsemoğlu, ${ }^{4}$ Ali Arslantaş \\ ${ }^{1}$ Dumlupınar Üniversitesi, Evliya Çelebi EAH, Radyoloji Kliniği, Kütahya,Türkiye \\ ${ }^{2}$ Dumlupınar Üniversitesi, Tıp Fakültesi, Nöroşirürji Anabilimdalı, Kütahya, Türkiye \\ ${ }^{3}$ Dokuz Eylül Üniversitesi, Biyomekanik Anabilimdalı, İzmir, Türkiye \\ ${ }^{4}$ Eskişehir Osmangazi Üniversitesi, Tıp Fakültesi, Nöroşirürji Anabilimdalı, Eskişehir,Türkiye
}

Özet: Toplumda ciddi sağlık problemleri arasında bulunan spinal travmalar, geçmiş yıllarda destekleyici yöntemlerle tedavi edilirken günümüzde implant özelliklerinin gelişmesiyle, yerini radyolojik görüntülemelerin de desteğiyle planlamanın daha iyi yapıldığı cerrahi tedaviye bırakmıştır. Günümüzün popüler yeniliklerinden olan 3 boyutlu yazıcılar hayatın her alanında olduğu gibi tıp alanında da her geçen gün daha fazla kullanılmaktadır. Bu çalışmanın amacı BT üzerinden bilgisayar destekli modelleme kullanılarak 3 boyutlu yazıcı yardımı ile birebir hastanın omurga modelleri üretilerek; cerraha ameliyat öncesi simülasyon imkanı sağlamaktır. Çalışmamızda spinal travma öyküsü olan hastaların direk grafi, bilgisayarlı tomografi; 3 boyutlu bilgisayarlı tomografi ile bilgisayar destekli omurga modelleri oluşturularak ve 3 boyutlu yazıcılarda üretilerek farklı cerrahlar tarafından cerrahi plan yapmaları sağlanacaktır.

Anahtar Kelimeler: omurga, 3D modelleme, cerrahi, radyolojik görüntüleme

Aydın N, Kaya İ, Hüsemoğlu Buğra R, Arslantaş A. 2017, Torakal Vertebra Görüntülemesinde Simülasyon ve Üç Boyutlu Modellemenin Radyolojik Tanı ve Cerrahi Öncesi Planlama Üzerinde Etkileri, Osmangazi Journal of Medicine 2017, 39(3)58-61 Doi: $10.20515 /$ otd.339193

\begin{abstract}
Spinal trauma, which is a serious health problem in the community, has been treated with supportive methods in the past years, nowadays, with the development of the implant properties, surgical treatment has been left where better planning is provided with support in radiological imaging. 3D printer, one of today's popular innovations, is used more and more every day in medicine as well as in every field of life. The aim of this study was to develop computerized modeling of the backbone models of the individual patient with the help of 3D printer by using computer aided modeling through IT; surgery is to provide pre-op simulation. Direct x-ray of the patients with spinal trauma history, computed tomography; Computerized backbone models with 3D computerized tomography will be created and 3D surveys will be produced by different surgeons to make surgical plans.
\end{abstract}

Key Words: spine, 3D simulation, surgery, radiological studies 


\section{Giriş}

Spinal travma ile ilgili ilk yazılara M.Ö 30002500 yıllar1 arasında yazılan Edwin Smith Papirüs'de rastlanmaktadır (1). Bilimsel tıbbın kurucularından olan Hipokrat vertebra anatomosi ve fizyolojisi ile ilgilenmiş ve yaklaşık M.Ö 400 yıllarında klinik bulgu olan paraplejiyi tarif etmiştir $(2,3)$. Günümüze gelindiğinde teknolojik gelişmelerle beraber sadece cerrahi yöntemler ve enstrümanlarda değil radyolojik tanı ve girişimsel tedavi yöntemlerinde de gelişmeler olduğu görülmüştür. Son y1llarda teknolojik gelişmeler arasında bulunan 3 boyutlu yazıcılar hayatın her alanında olduğu gibi medikal alanında da her geçen gün daha fazla kullanılmaktadır.

Radyolojik görüntülemeler incelendiğinde spinal travmalarda vertebra yapisinı değerlendirmede manyetik rezonans (MR) görüntülemenin yanında direk grafi ve bilgisayarlı tomografi (BT) hızlı, göreceli olarak ucuz oldukları için ilk tercih edilecek görüntüleme yöntemleridir. Farklı pozisyonlarda çekilen direk grafileri (fleksiyon ekstansyon ya da rotasyon) listezis gibi olası dinamik instabilitelerin tanısında yol göstericidir. Ancak BT kemik yapının değerlendirilmesi ve spinal kanal çapının ölçülmesinde daha etkilidir. MR kemik doku ile kas, yă $\breve{g}$ doku, ligamanlar spinal kord ayrımında diğer görüntüleme tetkiklerine üstünlük kurmaktadır. Manyetik olarak tarama gerçekleştirildiği için hasta açısından güvenilir bir tetkiktir (4).

Çalışmamızın amacı kliniğimize başvuran hastalarda BT üzerinden bilgisayar destekli modelleme kullanılarak 3 boyutlu yazıcı yardımı ile birebir hastanın omurga modelleri üretilerek; radyolojik tanıyı bir adım öteye götürmek ve cerrahi işlemi kolaylaştırmaktır.

\section{Materyal Method}

Son bir y1l içerisinde kliniğimize spinal travma ve ağrı şikayeti ile kabul ettiğimiz 20 hasta çalışmamıza alınmıştır. Hastalarımızın direk grafi (Shimadzu Radyografik Sistem), bilgisayarlı tomografi (Toshiba ALEXION 16-kesit Multi-detector); 3 boyutlu bilgisayarlı tomografi ile bilgisayar destekli radyoloji programları kullanılarak omurga modelleri oluşturulmuş ve 3 boyutlu yazıcılarda (Ultimaker 2 go) CPE filament ile üretilerek anatomik yapılar tam olarak ortaya koyulmuştur. CPE fillament 240/250 derece gibi yüksek 1sılarda daha sert bir yapıya sahip bir malzeme olduğundan dolayı modellemizde tercih edilmiştir.

\section{Bulgular}

Vertebra kırı̆̆ı tanısı olan hastalarımızda modelleme tam olarak yapılmıştır. Modeller üzerinde radyolojik görüntülemelerin 3 boyutlu karşıllğı sağlanmış bu sayede ameliyatı gerçekleştirecek cerrahi ekibe ameliyat öncesi simülasyon imkanı tanınmıştır. Radyolojik olarak bilgisayarlı tomografi verilerinin vertebra anatomisini tam olarak sağladığı görülmüştür.

\section{Tartıșma}

Son yıllarda farklı alanlarda kullanımı ile popüler olan 3 boyutlu yazıcılar ile ilgili çalışmalar sınırlıdır. Medikal alanda özellikle ortopedi ve beyin cerrahi kliniklerince yapılmış olan çalışmalar irdelenmiş ve radyolojik görüntülerin tabanında somut verilerin elde edildiği görülmüştür.

Joshua P. Klein ve arkadaşları 2015 yılında yayınladıkları makalelerinde omurga görüntülemeleriyle ilgili bir yol haritası belirlemişlerdir. Makalede omurga görüntüleme yöntemlerinin s1klıkla kullanıldığı ve bu görüntülerin doğru yorumlanması için sistematik bir yaklaşım gereksiniminden bahsedilmiştir (4).

Jae-Young Hong ve arkadaşlarının bilgisayarlı tomografinin 3 boyutlu deformitelerin kavranmasındaki etkinliğini inceledikleri çalışmada hastalara operasyon öncesi ve sonrası tüm omurga direk grafileri ve bilgisayarlı tomografilerde vertebral rotasyon, rib humb indeks ve sternal shift oranlarını ölçmüşler ve bilgisayarlı tomografinin 3 boyutlu deformitelerin belirlenmesinde, tedavinin planlanmasında ve cerrahi sonuçların değerlendirilmesinde faydalı bir yöntem olduğunu ortaya koymuşlardır. (5) Çalışmamızda bu 3 boyutlu görüntüleme yöntemini radyolojik verileri kullanarak cerrahlara, omurganın somut biçimde üretilmiş, üzerinde inceleme ve işlem yaptığ 1 bir modeli hazırladık. 
Perez-Mananes ve arkadaşları 3 boyutlu modellemeyi ortopedi kliniğinde uygulamış ve bu yöntemle cerrahi süresi, skopi kullanım süresi ve deformite düzeltme oranlarını karşılaştırmışlardır. Sonuç olarak ameliyat öncesi modellemenin cerrahi süreyi kısaltırken hata payını azalttığını göstermişlerdir (6). Diğer bir çalışmada 1'e 1 boyutlarında hazırlanan 3 boyutlu modellerin dokunsal ve görsel açıdan başarılı bir deneyim sağladıklarını belirtmişlerdir (7).

Üç boyutlu yazıcılarla omurga modellerinin basımını araştıran bir çalışmada bu baskının güvenilir bir yöntem olarak kullanılabileceğini göstermişlerdir. Üretilen 3 boyutlu omurga modellerinin üretiminin yaygınlaşmasıyla kadavra temini gibi imkanların kısıtlı olduğu konularda araştırmacılar için iyi bir alternatif olduğunu belirtmişlerdir (8).

Karlin ve ark. yaptığı 17 çocuk hastayı kapsayan çalışmasında, çocuklarda spinal deformiteyi düzeltmek için kişiye özel 3D printer modelleri kullanılmıș. Preop 3D printer modellerini kullanan grupta, cerrahi süre, skopi kullanımı ve kan kaybı az olarak saptanmıştır (9). Pediatrik problemlerde üç boyutlu modellerle birlikte cerrahlar klasik 2 boyutlu radyolojik görüntülere göre daha somut bir şekilde hasta anatomisini inceleme ve daha kolay tanı koyma imkânına sahip olmuşlardır(1).

Geleceğe yönelik planlamalar düşünüldügünde, deneysel çalışmalarda kisiye özel füzyon materyalleri deneysel olarak üretilmiştir ve gelecekte bu yöntemin kişiye özel implant yapımını sağlayağını belirtmişlerdir (10).

Üç boyutlu yazıcıların desteğiyle radyolojik görüntülemeler somut objelere dönüştürülmüş ve bu sayede cerrahi öncesi planlamayla birlikte cerrahi süresinin kısaldığ 1 görülmüştür. Cerrahi sırasında skopi kullanım süresinin k1salması, hem hastay1 hem de cerrahları koruyan çift taraflı bir kazanımdır. Radyolojik görüntülemelerin desteklediği üç boyutlu yazıcilarla üretilen modeller hem doktorların hem de hastaların mevcut patolojiyi anlamalarına ve preoperatif plan yapılmasina olanak vermektedir.

\section{Sonuç}

Radyolojik görüntülemelerin desteğiyle birlikte cerrahi öncesi modelleme sayesinde cerrahi planlama yapılmış ve işlemin stimule edilmesine olanak sağlanmıştır. Üç boyutlu bask1 teknolojisindeki gelişmelerle beraber model üretim hızının artması, maliyetlerin düşmesi 3 boyutlu yazdırılmış modellerle preop planlama cerrahi simulasyonlar, intraoperative k1lavuz kullanımı rutin uygulama haline gelebilir. Gelişen teknoloji ile birlikte güncel tanı yöntemlerine ek olarak 3D yazıcılar sayesinde üretim yapılmasının işlemi uygulayacak cerrahlara yön gösterici olacağını düşünüyoruz.

\section{KAYNAKLAR}

1. Agrawal SK, Fehlings MG. Mechanisms of secondary injury to spinal cord axons in vitro: Role of $\mathrm{Na}$, Na-K ATPase, the NA-H exchanger and the $\mathrm{Na}-\mathrm{Ca}$ exchanger. J. Neuroscience. 1996;16 (2):545-552.

2. İplikçioglu C. Omurilik yaralanmasının fizyopatolojisi. Omurilik Omurga Cerrahisi, Ed. M.Zileli, Fahir Özer, 1. Baskı, İzmir, Saray Medikal Yayınc1lık, 2002, s: 459-465

3. Naderi S, M.Zileli, A. Fahir Özer: Omurga Cerrahisinin Tarihçesi, Omurilik ve Omurga Cerrahisi Ed. M. Zileli, Fahir Özer, 2. bask1, cilt 1, Meta Basım, Bornova, İzmir 2002, s:113

4. A Practical Approach to Spine Imaging. CONTINUUM: Lifelong Learning in Neurology,. Klein, J. P. 36-51, : (1, Spinal Cord Disorders), 2015, Cilt 21.

5. Hong JY, Suh SW, Easwar TR, Modi HN, Yang JH, Park JH. Evaluation of the three- dimensional deformities in scoliosis surgery with computed tomography: efficacy and relationship with clinical outcomes. Spine. 2011;36(19):1259-65.

6. Chana-Rodríguez F, Mañanes RP, RojoManaute J, Gil P, Martínez-Gómiz JM, Vaquero-Martín J. 3D Surgical Printing Cutting Guides for Open-Wedge High Tibial

7. Osteotomy: Do It Yourself. Injury. 2016; 47(11):2507-11.

8. Starosolski ZA, Kan JH, Rosenfeld SD, Krishnamurthy R, Annapragada A. Application of 3-D printing (rapid prototyping) for creating physical models of pediatric orthopedic disorders. Pediatr Radiol. 2014;44(2):216-21.

9. Wu AM, Shao ZX, Wang JS, Yang XD, Weng WQ, Wang XY, Xu HZ, Chi YL, Lin ZK. The accuracy of a method for printing 
three-dimensional spinal models. PLoS One. 2015 Apr 27;10(4):e0124291.

10. Karlin L, Weinstock P, Hedequist D, Prabhu SP. The surgical treatment of spinal deformity in children with myelomeningocele: the role of personalized three-dimensional printed models. J Pediatr Orthop B. 2017;26(4):375382.

11. Provaggi E, Leong JJH, Kalaskar DM. Applications of 3D printing in the management of severe spinal conditions. Proc Inst Mech Eng H. 2017 Jun;231(6):471-486. 